\title{
Association between beliefs and attitudes of youth towards ARVs and sexual risky behaviors in Botswana
}

\author{
Mpho Keetile* \\ University of Botswana, Gaborone, Botswana
}

*Corresponding author: Mpho Keetile, University of Botswana, Gaborone, Botswana, Tel: (267) 71231375; Fax: (267) 355 4721; E-mail: mphokeet@yahoo.com; mpho.keetile@mopip.ub.bw

Received date: January 20, 2015; Accepted date: February 25, 2015; Published date: March 3, 2015

Copyright: $\odot 2015$ Keetile M, et al. This is an open-access article distributed under the terms of the Creative Commons Attribution License, which permits unrestricted use, distribution, and reproduction in any medium, provided the original author and source are credited.

\begin{abstract}
In Botswana no study has examined the association between beliefs and attitudes of young people towards ARVs and sexual risky behaviors. This paper aims to assess the association between beliefs and attitudes of youth about ARVs and sexual risk behaviors. It is based on secondary data derived from the Botswana AIDS Impact Survey IV (BAIS IV) which is the latest survey aimed at providing up to date information on HIVIAIDS pandemic in Botswana. A sample of 2632 youth in ages $15-24$ years was considered for analysis. About $11 \%$ of youth in the sample were of the view that people on ARVs should not always use condoms, $5 \%$ believed ARVs cure AIDS, and $52 \%$ said that their personal concern about getting HIV has not changed since the introduction of ARVs. Logistic regression results indicate statistically significant association between having multiple sexual partners and the belief that people on ARVs should not always use condoms (AOR, 1.5), and belief that a person on ARVs should stop taking them once they feel better (AOR, 2.5). Moreover, young people who said that their personal concern about getting HIV has not changed (AOR, 1.04) or those less concerned (AOR, 1.6) about getting HIV since the introduction of ARVs were more likely to have multiple sexual partners. Meanwhile, there was no significant association observed between some beliefs and attitudes about ARVs and inconsistent condom use, except for young people who said that they are less concerned about getting HIV since the introduction of ARVs (AOR, 9.9). Beliefs and attitudes of youth about ARVs suggest that more education efforts need to be incorporated in HIV care and treatment to reduce risky sexual behaviors and HIV transmission among youth.
\end{abstract}

Keywords Beliefs; Attitudes; Youth; Antiretroviral treatment; Sexual risk behavior

\section{Introduction}

In Botswana, morbidity and mortality for all ages are still dominated by infectious diseases with HIV/AIDS and its related illnesses causing about half of the deaths [1]. However, with the introduction of Antiretroviral (ARVs) program in 2002, HIV/AIDS mortality has been declining over the years, even though it is still a major concern. The primary goal of antiretroviral therapy is to improve the quality of life of People Living with HIV/AIDS (PLWHA) by slowing the progression of the virus to AIDS illness [2]. Botswana's access to ARVs has been estimated to have increased to $87 \%$ in 2011and has been hailed as the most successful in sub-Saharan Africa [1]. Although Botswana's ARVs program is considered successful, it presents potential challenges of sexual risk behavior associated with availability of ARVs observed in other settings.

Consistent use of condoms with regular partners among young people has been reported to be too low among youth in Botswana [3]. In the Botswana AIDS Impact Survey III (BAIS III), only $17 \%$ of those aged 20-24 years reported always using a condom with regular partners [4]. Programs for young adults and older age groups such as the routine HIV testing, ARV treatment, and condom promotion have been observed to be very good in terms of quality and coverage, but relatively weak in terms of education and information [5]. Studies from other settings have shown that there is a strong association between beliefs and attitudes of people about ARVs availability and sexual risky behaviors [6-8]. Such studies have clearly shown that beliefs and attitudes about HIV treatment programs have led to increases in unprotected sexual intercourse and multiple sexual partnerships.

Sweat et al. [6] observed that enhanced availability of HIV treatment programs, such as ARVs, are likely to facilitate HIV prevention by reducing stigma and increasing HIV testing rates. However, an overemphasis on treatment programs such as ARVs could also detract from prevention efforts and lead to reduced public concern about HIV and increased HIV risk behaviors [5]. In the United States and Europe, for instance, it was observed that since the introduction of ART in 1996 there was an upward trend in non-use of condoms among heterosexual and homosexual couples $[4,6]$. More specifically, an association was identified between decreased concern about HIV due to ARVs availability and unprotected sexual intercourse [4]. Lending further support to these findings, a longitudinal study of gay couples in the Netherlands concluded that participants who perceived HIV/AIDS as less threatening since availability of ARVs had higher incidence of sexually transmitted infections and HIV [8].

A systematic review of literature on the impact of ARVs on sexual risk behaviors in sub Saharan Africa by Kennedy et al. [9] showed that provision of ART is associated with improvements in sexual riskbehavior indicators, such as condom use with both infected and uninfected partners and declining rates of contagious incidence among partners of HIV-infected individuals. However, a study in Uganda, Kisumu [10] showed that there was strong association in the opinions and attitudes of people towards ART and unprotected sexual 
Page 2 of 8

intercourse which ultimately led to high HIV-seroprevalence. Early mathematical models suggest that even modest increases in sexual risk behaviors which result from ARVs availability may offset the potential protective benefits of wider treatment access [11].

Although some studies and surveys have been done on HIV/AIDS and youth in Botswana including the Youth Risk Behavioral Surveillance Survey (YRBSS-2010), such studies or surveys have focused more on measuring and classifying adolescent risk behaviors $[8,12,13]$ and none have looked at the association between availability of ARVs and sexual risk taking. In Botswana, no study has been undertaken to make an assessment of beliefs and attitudes of youth towards ARVs and the influence beliefs and attitudes on risky sexual behaviors such as multiple concurrent partnerships and unprotected sexual intercourse. The main aim of this paper is to assess how availability of ARVs has influenced sexual risk behaviors among youth in Botswana.

\section{Theoretical orientation}

Some theories and models have been developed and used to understand health seeking behavior and health outcomes among youth and the general population. The common general model that has been used for analysis of health seeking behavior is the health belief model, which has been often used as all-encompassing in health related studies. However, there are several other models/theories used for studying health behavior of individuals such as the theory of reasoned action and planned behavior; risk reduction model and other models.

These models and frameworks have been useful in improving the understanding of other health behaviors and outcomes, despite the fact that they have been unable to explicitly interpret the social reasoning underlying the spread of HIV-AIDS among youth. Some studies [14] have shown that social cognitive theory seems relevant and could be used to guide research on HIV/AIDS related attitudes and beliefs among youth, as well as the development of AIDS prevention programs designed for youth. One of the researchers who have used social-cognitive framework, Bandura [14], has consistently shown that people learn from a variety of experiences, including their own, and by observing the behavior of other people in their community. The theory predicts that youth will be better able to engage in positive self-directed change of their attitudes and beliefs if they have knowledge about HIV/AIDS and its medication [14]. Therefore, young people who are less knowledgeable about the use of
HIV/AIDS medication such as ARVs and those who have some other adverse health beliefs are most likely to engage in sexual risky behavior, such as inconsistent condom use or having multiple sexual partners as they do not perceive themselves to be at risk.

In line with Bandura's [14] social-cognitive framework, this study adopts to assess the influence of certain beliefs and attitudes of youth about ARVs on their sexual behavior based on a set of variables. Sexual behaviors of youth are postulated to be influenced by the respondent's characteristics (such as sex, age, education, residence, religion, and some attitudes and beliefs about ARVs). It is understood that the respondent's characteristics work to affect the respondent's perception of medication such as ARVs. Respondents' beliefs and attitudes together with their background have a bearing in the changing traditional and cultural opinions about HIV and therefore their attitudes. Thus, respondents with erroneous beliefs and attitudes about ARVs are likely to indulge in sexual risk behavior.

\section{Methodology}

\section{Data}

This paper uses secondary data derived from the fourth and latest Botswana AIDS Impact Survey. The main objectives of the BAIS IV include providing latest information on the national HIV prevalence and incidence estimates among the population 6 months and above; to provide indicative trends in sexual and preventive behavior among the population aged 10-64 years; and to provide a comparison between HIV rate, behavior, knowledge, attitude, poverty and cultural factors that are associated with the epidemic with estimates derived from previous surveys. BAIS IV employed a national two stage sample survey design. Data collection was done using smart phone tablets instead of the conventional paper based method. Estimates for response rates showed that $83.9 \%$ of persons aged 10 to 64 answered individual questions. The data also showed that $73.4 \%$ of population 6 weeks and above participated in HIV testing. The targeted sampled population (aged 10-64 years) for BAIS IV was 9,807 [10].

\section{Sample Selection}

For this paper the sample was restricted to only people 15-24 years old which resulted in a sample size of 2632 . HIV/AIDS prevalence rate was estimated at $8.8 \%$ for the $15-19$ year olds, while for $20-24$ years old cohort it was $10.3 \%$ [10] (Table 1).

\begin{tabular}{|l|l|l|l|}
\hline Target population & Sampled Population & Responded population & Response rate (\%) \\
\hline Individuals (10-64 years) & 9.807 & 8.321 & 83.9 \\
\hline DBS (6 Weeks and above) & 13.808 & 10.140 & 73.4 \\
\hline Tested and want HIV results & 10.140 & 8.070 & 79.6 \\
\hline \multicolumn{2}{|l|}{ Source: Statistics Botswana (2013)-Preliminary results for Botswana Aids Impact Survey IV (BAIS IV), 2013 } \\
\hline
\end{tabular}

Table 1: Un-weighted data of sampled population by target population and response rate for BAIS IV.

\section{Measurement of variables}

Two dependent variables indicative of risky sexual behaviors were used in this paper, namely, condom use inconsistency and multiple sexual partnerships.
Condom use inconsistency was measured by responses to questions that sought to find out if respondents had always used a condom with their past three sexual partners. The following questions were used to create a composite index for condom use inconsistency as used in this paper; i) In the past 12 months have you always used a condom with 
Page 3 of 8

this partner?-(partner1-most recent sexual partner) ii) In the past 12 months have you always used a condom with this partner?-(partner 2next most recent sexual partner) and iii) In the past 12 months have you always used a condom with this partner?-(partner 3-second most recent sexual partner). A dichotomous composite variable was then derived and used to measure condom use inconsistency. The resultant variable was coded such that 1 was given to denote condom use inconsistency and 0 to denote that condom has been used consistently with the past three partners

Multiple sexual partnership variables were derived from the item; in the last 12 months with how many people overall have you had sex? This variable was coded such that 1 denoted respondents who had more than one sexual partner in the past 12 months (multiple sexual partners) and 0 if respondents said they had one or no sexual partner.

BAIS IV had an 8 item section with questions relating to beliefs and attitudes about ARVs. The main independent variables for this paper relate to the following questions on beliefs and attitudes of respondents about ARVs.

What do you believe antiretrovirals (ARVs) do? Response options were; $1=$ =Cure AIDS $2=$ Cure HIV $3=$ =Supress HIV and $4=$ don't know. Response 1 and 2 were combined and coded 1 , response 2 was given code 0 , while response 4 (don't know) was filtered out.

Has your personal concern about getting HIV changed since the introduction of ARVs? Responses were $1=y e s$ and $2=$ no, and were recoded as $1=$ yes and no $=0$

How has your personal concern about HIV changed since the introduction of ARVs? Response options for this question were; $1=$ less concerned, 2=more concerned (recoded as $1=$ less concerned and $0=$ more concerned) and $3=$ don't know. Don't know response was filtered out.

Do you think that people on ARVs should always use condoms? Response options were; $1=y e s, 2=$ no and the codes were as $1=$ yes and $0=$ no. Don't know was filtered out.

Do you think a person on ARVs should discontinue/stop taking them once they feel better? Response options were; $1=y e s, 2=$ no and recodes were $1=$ yes and $0=$ no, while don't know response was filtered out.

Socio-demographic variables such as sex, age, education, religion and place of residence were used as control variables.

\section{Statistical methods of data analysis}

Data analysis for this paper was done using Statistical Package for Social Sciences (SPSS), version 22 program. Descriptive analysis was done and results were presented as frequencies and percentages to describe participants and their beliefs and attitudes about ARVs. Binary logistic regression analysis was also done to assess the effect of selected group of beliefs and attitudes about ARVs on the probability of not using condoms consistently or having multiple concurrent sexual partners while controlling for other potential confounders. Two logistic regression models were run for each of the two dependent variables. Model 1 only predicts the effects of beliefs and attitudes about ARVs on the dependent variables (inconsistent condom use and multiple sexual partnerships) while Model 2 introduces the control

$1 \quad$ Derived from De Maris A (1992) Logit Modelling: Practical applications. Sage, London pp: 87. variables to predict the effects of beliefs and attitudes about ARVs on the two dependent variables while controlling for socio-demographic variables. Results of logistic regression are presented as crude Odds Ratios (OR) for model I and Adjusted Odds Ratios (AOR) for model II.

\section{Gross effects logit model}

This model examines the relationship between independent variables and dependent variables. ${ }^{1}$ For the association between each dependent variable and the independent variable the model can be expressed as follows;

$$
y=\alpha+\beta_{1}+X_{1}
$$

Where $y$ is the likelihood that an individual will perform sexual risk behavior, $\beta_{1}$ is the baseline constant and $X_{1}$ is an independent variable.

\section{Net effects logit model}

The relationship between an independent variable and dependent variable, while simultaneously controlling for the effects of other variables, was examined using the net effects logistic regression model. For net effects model, variables mediating for beliefs and attitudes were entered together with socio-demographic to assess the influence of beliefs and attitudes of you about ARVs while holding constant the effect of background variables. This allowed for the prediction of the significance of a given predictor while controlling for all other predictors in the model and the model was presented as;

$$
y=\alpha+\beta 1+X_{1}+\Sigma \beta_{\mathrm{k}} X_{\mathrm{ki}}
$$

Whereby y is the probability than an individual performs sexual risk behavior, $\beta_{1}$ is the baseline constant; $X_{\mathrm{ki}}$ is an array of $(\mathrm{k})$ independent or control variables and $\beta$ is the corresponding vector of unknown regression coefficients.

\section{Results}

\section{Sample characteristics}

Table 2 results indicate that out of a sample of 2632 respondents, there were slightly more female (52\%) than male youth (48\%). There were slightly high proportion of youth in ages $20-24$ (51\%), than in ages 15-19 years (49\%), while respondents with secondary education (45\%) and primary education (39\%) were the most predominant in the sample. More than two thirds (67\%) of respondents were from rural areas, while the remaining one third were from urban areas $(34 \%)$. Most respondents were of the Christian religion (87\%), followed by no religion (9\%) and other-non Christian religions (4\%) were the least represented in the sample.

\section{Beliefs and attitudes of youth towards ARVs by sex}

Results of Table 3 show that about $5 \%$ of respondents had belief that ARVs cure AIDS, and this is equal for both men and women. A high proportion of men (54\%) than women (51\%) reported that their personal concern about getting HIV/AIDS has not changed since the introduction of ARVs, while a slightly high proportion of women (32\%) than men (31\%) said that they were less concerned about HIV 
Citation: Keetile M (2015) Association between beliefs and attitudes of youth towards ARVs and sexual risky behaviors in Botswana. J AIDS Clin

since the introduction of ARVs. More women (11\%) than men (10\%) were of the view that people on ARVs should not always use condoms, while $5 \%$ of both men and women thought that a person on ARVs should discontinue/stop taking them once they feel better.

\begin{tabular}{|c|c|c|}
\hline Characteristic & Percent & Number $(\mathrm{N}=2632)$ \\
\hline \multicolumn{3}{|l|}{ Sex } \\
\hline Male & 48.3 & 1271 \\
\hline Female & 51.7 & 1361 \\
\hline \multicolumn{3}{|l|}{ Age } \\
\hline $15-19$ & 49.2 & 1296 \\
\hline $20-24$ & 50.8 & 1336 \\
\hline \multicolumn{3}{|l|}{ Education } \\
\hline Non-formal & 0.7 & 18 \\
\hline Primary & 38.7 & 1018 \\
\hline Secondary & 44.5 & 1171 \\
\hline Tertiary & 16.2 & 425 \\
\hline \multicolumn{3}{|l|}{ Residence } \\
\hline Urban & 33.5 & 882 \\
\hline Rural & 66.5 & 1742 \\
\hline \multicolumn{3}{|l|}{ Religion } \\
\hline Christianity & 87.4 & 2300 \\
\hline Other non-Christian & 3.8 & 100 \\
\hline No religion & 8.8 & 232 \\
\hline
\end{tabular}

Table 2: Socio-demographic characteristics of youth who participated in BAIS IV.

\begin{tabular}{|c|c|c|c|}
\hline Characteristic & Male & Female & Total $(\mathrm{N}=\mathbf{2 6 3 2})$ \\
\hline \multicolumn{4}{|c|}{ What do you belief antiretroviral (ARVs) do? } \\
\hline Cure HIVIAIDS & 4.6 & 4.6 & 121 \\
\hline Suppress HIV & 95.4 & 95.4 & 2511 \\
\hline \multicolumn{4}{|c|}{ Has your personal concern about getting HIV changed since the introduction of ARVs? } \\
\hline Yes & 46.1 & 49.0 & 1255 \\
\hline No & 53.9 & 51.0 & 1377 \\
\hline \multicolumn{4}{|c|}{ How has your personal concern about HIV changed since the introduction of ARVs? } \\
\hline Less concerned & 30.8 & 31.6 & 821 \\
\hline More concerned & 69.2 & 68.4 & 1811 \\
\hline \multicolumn{4}{|c|}{ Do you think that people on ARVs should always use condoms? } \\
\hline Yes & 89.7 & 88.9 & 2350 \\
\hline No & 10.3 & 11.1 & 282 \\
\hline
\end{tabular}


Citation: Keetile M (2015) Association between beliefs and attitudes of youth towards ARVs and sexual risky behaviors in Botswana. J AIDS Clin

\begin{tabular}{|l|l|l|l|}
\hline Better? & 5.0 & 5.4 & 137 \\
\hline Yes & 95.0 & 94.6 & 2495 \\
\hline No & & \multicolumn{3}{l|}{} \\
\hline
\end{tabular}

Table 3: Distribution of beliefs and attitudes of youth towards ARVs according to sex, Botswana, 2012.

\section{Binary logistic regression results}

Gross effects model on inconsistent condom use among youth with certain beliefs and attitudes about ARVs: Model I results indicate no significant association between beliefs and attitudes about ARVs and inconsistent condom use. For instance, results show no statistical significance between the belief that ARVs cure HIV/AIDS and inconsistent use of condom, while youth who said that their personal concern about getting HIV since the introduction of ARVs has not changed were $26 \%$ less likely (OR, 0.74, C.I $=0.67-0.80)$ to report inconsistent condom use. Furthermore, youth who thought that people on ARVs should always use condoms were $83 \%$ less likely (OR, 0.17 , C.I $=0.13-0.23)$ to have used condoms inconsistently themselves, while those who were of the view that a person on ARVs should discontinue/stop taking them once they feel better were $61 \%$ less likely (OR, 0.39, C.I $=0.33-0.47)$ to report inconsistent condom use. These results are against the expected norm because individuals with adverse beliefs and attitudes are expected to indulge in sexual risk behavior (Table 4).

\begin{tabular}{|c|c|c|c|c|}
\hline Variable & Model I & $95 \%$ C.I & Model II & $95 \%$ C.I \\
\hline \multicolumn{5}{|c|}{ What do you believe antiretroviral (ARVs) do? } \\
\hline Cure HIVIAIDS & 0.39 & $0.327,0.472$ & 0.00 & 0.00 \\
\hline Suppress HIV & 1.0 & - & 1.0 & - \\
\hline \multicolumn{5}{|c|}{ Has your personal concern about getting HIV changed since the introduction of ARVs? } \\
\hline Yes & 1.0 & - & 1.0 & - \\
\hline No & $0.74^{\star}$ & $0.671,0.808$ & 0.38 & $0.326,0.472$ \\
\hline \multicolumn{5}{|c|}{ How has your personal concern about HIV changed since the introduction of ARVs? } \\
\hline Less concerned & $0.09^{*}$ & $0.066,0.124$ & $9.91^{*}$ & $7.289,13.64$ \\
\hline More concerned & 1.0 & - & 1.0 & - \\
\hline \multicolumn{5}{|c|}{ Do you think that people on ARVs should always use condoms? } \\
\hline Yes & 1.0 & - & 1.0 & - \\
\hline No & $0.17^{*}$ & $0.125,0.233$ & $0.40^{*}$ & $0.321,0.611$ \\
\hline \multicolumn{5}{|c|}{ Do you think a person on ARVs should discontinue/stop taking them once they feel better? } \\
\hline Yes & $0.39^{*}$ & $0.327,0.472$ & 0.00 & 0.00 \\
\hline No & 1.0 & - & 1.0 & - \\
\hline \multicolumn{5}{|l|}{ Sex } \\
\hline Male & & & 1.0 & - \\
\hline Female & & & $0.56^{*}$ & $0.482,0.655$ \\
\hline \multicolumn{5}{|l|}{ Age } \\
\hline $15-19$ & & & 1.0 & - \\
\hline $20-24$ & & & $0.20^{*}$ & $0.212,0.278$ \\
\hline \multicolumn{5}{|l|}{ Education } \\
\hline Non-formal & & & $0.11^{*}$ & $0.093,0.124$ \\
\hline Primary & & & $0.33^{*}$ & $0.287,0.384$ \\
\hline
\end{tabular}


Page 6 of 8

\begin{tabular}{|c|c|c|}
\hline Secondary & $0.31^{*}$ & $0.285,0.382$ \\
\hline Tertiary & 1.0 & - \\
\hline \multicolumn{3}{|l|}{ Residence } \\
\hline Urban & 1.0 & - \\
\hline Rural & 0.91 & $0.805,1.039$ \\
\hline \multicolumn{3}{|l|}{ Religion } \\
\hline Christianity & 1.0 & - \\
\hline Other non-Christian & $2.30^{*}$ & $1.934,2.747$ \\
\hline No religion & $18.7^{*}$ & $14.95,23.49$ \\
\hline
\end{tabular}

Table 4: Odds ratio (OR) for the probability of inconsistent condom use among youth.

Net effects model on inconsistent condom use among youth with certain beliefs and attitudes about ARVs: Net effects logistic regression (Model II) results indicate that after including the control variables in the model, the association between inconsistent condom use and the belief that ARVs cure HIV/AIDS did not produce any statistical meaningful outcomes. Furthermore, there was no significant statistical association for youth with less concern about HIV since the introduction of ARVs and inconsistent condom use. Young people, who said that they were less concerned about getting HIV/AIDS since the introduction of ARVs, were 9 times (AOR, C.I=7.29-13.6) more likely to have used condoms inconsistently than those who were more concerned while those who thought that a person on ARVs should discontinue or stop taking them once they feel better were less likely (AOR, 0.4,C.I $=0.32-0.61$ ) to have used condoms inconsistently compared to those who thought otherwise.

Female youth were less likely (AOR, 0.56, C.I $=0.48-0.66$ ) to have used condom inconsistently than their male counterparts, while young persons in ages 20-24 years were also less likely (AOR, 0.2, C.I $=0.19-0.28)$ to report inconsistent use of condom compared to those in ages 15-19 years. There was no significant $s$ tatistical association between inconsistent condom use and place of residence, while for religion, respondents of other non-Christian religions were 2 times (AOR, 2.3, C.I=1.93-) more likely to have used condom inconsistently with their past 3 sexual partners, while those with no religion were about 19 times (AOR, 18.7, C.I=14.9-23.5) more likely to have not used condoms consistently with their past 3 sexual partners compared to youth of Christian religion.

Gross effects model on the probability that youth with certain beliefs and attitudes had multiple sexual partners in the past twelve months: Model I results indicate no statistically significant association between having multiple sexual partners and beliefs and attitudes of youth towards ARVs. For instance, young people who believe that ARVs cure HIV/AIDS were less likely (OR, 0.41, C.I=0.38-0.41) to have multiple sexual partners compared to those who did not belief ARVs cure HIV/AIDS. Moreover, youth who said that their personal concern about getting HIV since the introduction of ARVs has not changed were less likely $(\mathrm{OR}, 0.17$, C.I $=0.16-0.17)$ to have multiple sexual partners, while also individuals who thought that people on ARVs should always use condoms were less likely (OR, 0.29, C.I $=0.28-0.30)$ to have reported multiple sexual partners compared to the reference group. Young people who thought that a person on ARVs should stop/discontinue taking them once they feel better were also less likely to have multiple sexual partners.

Net effects model on the probability that youth with certain beliefs and attitudes had multiple sexual partners in the past twelve months: Model II results indicate that after controlling for potential confounders such as sex, age, education, religion and residence, there was significant association between certain beliefs and attitudes about ARVs and having multiple sexual partners. For instance, young people who said that their personal concern about getting HIV has not changed since the introduction of ARVs were $4 \%$ more likely (AOR, 1.04 , C.I. $=1.01-1.07$ ) to have had multiple sexual partners compared to those whose concern had changed, while youth who said that they were less concerned about getting HIV since the introduction of ARVs were 1.6 times more likely (AOR, 1.61, C.I.=1.55-1.69) to report multiple sexual partners compared to those who were more concerned about getting HIV since availability of ARVs.

Youth who said that they think people on ARVs should not always use condoms were 1.5 times more likely $(A O R, 1.52$, C.I. $=1.49-1.69)$ to report having multiple sexual partners than those who thought otherwise. Meanwhile, those who said that they think that a person on ARVs should stop/discontinue taking them once they feel better were 2.5 times more likely (AOR, 2.51, C.I. $=2.36-2.59)$ to have had multiple sexual partners in the past twelve months. Women were less likely to report multiple sexual partners compared to men. Furthermore, the odds of having multiple sexual partners were significantly lower among youth in ages $20-24$ years $(A O R, 0.29$, C.I. $=0.28-0.30)$ than in ages 15-19 years, also among youth with non-formal, primary education than among those with tertiary education. The odds of having multiple sexual partners were also lower among young people living in rural areas (AOR, O.86, C.I. $=0.83-0.88$ ) than among those living in urban areas, while youth who said they had no religious affiliation were 2.6 times (AOR, 2.62, C.I. $=2.47-2.76)$ more likely to report multiple sexual partners than young people who were of Christian religion, conversely young people of other non-Christian religions were less likely report having multiple sexual partners than Christian youth. 


\section{Discussion}

Botswana has made significant progress in developing and promoting HIV prevention and treatment programs. The national ART program has grown and scaled-up treatment for HIV positive people. As shown in some other studies [15-20] the introduction of ARVs has led to sexual risk behaviors such as multiple sexual partnerships and inconsistent condom use. Analysis in this paper has shown similar patterns of sexual risk behaviors associated with ARVs availability as observed in some other previous studies, especially the association between certain beliefs and attitudes about ARVs and having multiple sexual partners.

It has been observed from the analysis that youth who reported that they were less concerned about getting HIV/AIDs since introduction of ARVs had the propensity to use condoms inconsistently. Similar findings were made in Kenya [17] and Uganda [19] that respondents who had some adverse beliefs about ART did not use condoms consistently. These studies have clearly and consistently indicated that the belief that people on ARVs should not always use condoms is buttressed by the belief that ARVs cure HIV/AIDS, hence individuals condone the misconception that when an individual is on ARVs it means that they are cured of HIV/AIDS. It has been shown that, availability of ARVs reduces the risk of HIV transmission through its effect of lowering both plasma and genital tract viral load [19,21,22], and that potential prevention modalities including ARVs may inhibit safer behaviors by reducing individuals' perceptions of their risk of infection [23]. While condom use has been associated with more than $90 \%$ reduction in risk of HIV acquisition [23], condoms should be used consistently and correctly for them to be efficacious.

Even though this study and other previous studies highlight positive association between ARVs availability and sexual risk behaviors, especially inconsistent condom use, some studies in other countries observed no significant association between beliefs and attitudes of people about ARVs and inconsistent condom use [19,20,24]. More recent models promoting testing and treating strategies, for example in the United States, assume that sexual risk behaviors do not increase with antiretroviral treatment coverage [25]. Furthermore, a metaanalysis assessing the impact of ARVs on sexual risk behaviors concluded that in some countries, rates of unprotected sex did not differ between those receiving treatment compared to those who were not, while those who perceived that ARVs might reduce HIV transmission had significantly higher levels of sexual risk behaviors [26]. There is need, to incorporate comprehensive education and information with the giving out of ARVs, to cancel adverse myths which ultimately lead to sexual risk behaviors in Botswana.

The risk of HIV infection and transmission depend on factors such as, the person who an individual has sexual intercourse with, whether that person has HIV or not and more importantly on number of sexual partners one has over a short period of time. The association between beliefs and attitudes of youth about ARVs and having multiple sexual partners was more apparent from the analysis. For instance, youth who believed that a person on ARVs should not always use condoms and those who thought that a person on ARVs should stop/discontinue taking them once they feel better were involved in multiple sexual partnerships. Moreover, young people who said that they were less concerned about getting HIV/AIDS since the introduction of ARVs reported multiple sexual partners. A similar observation was made by Cohen et al. [17] in Kenya, that people who had adverse beliefs and attitudes reported concurrent multiple sexual unions. Although, there are few studies that link multiple sexual partners to ARVs availability, some studies have shown that adverse beliefs or misinformation about HIV or its medication can lead to risky sexual behaviors in populations $[18,20,27]$.

Furthermore, results indicate that young men who had certain beliefs about ARVs reported multiple sexual partnerships compared to their women counterparts. Carter et al. [20] also observed that multiple sexual partnerships were common among men in Botswana, while Letamo and Bainame [24] opines, that in Botswana having many sexual partners is an attestation to men's masculinity hence this explains why even male youth also indulge in such practice. Multiple sexual t partnerships are endorsed by certain cultural and social norms that condone such behavior especially among men, but it becomes even more risky in the context of high HIV/AIDS prevalence as is the case in Botswana. High education level was associated with multiple sexual partnerships. This could also be associated with low HIV risk perception and adherence to cultural and social norms endorsing multiple sexual partnerships among people of certain socio-economic status. Differing results have been observed in different settings to highlight the complexity of measuring association between ARVs use and sexual risk behaviors. However, the case of Botswana is different as is the case in Uganda where a study conducted among HIVuninfected non spousal household members of adults taking ART found that perceiving HIV as curable was significantly associated with multiple partners and risky sexual behavior.

\section{Conclusion}

An understanding of the association between beliefs and attitudes of youth towards ART and risky sexual behaviors is vital for proper characterization of programs and interventions aimed at reduction of HIV prevalence. This paper has indicated significant association between adverse beliefs and attitudes about ARVs and having multiple sexual partners. Information provided by this analysis have fundamental policy implications for identifying relevant interventions and designing targeted cost-effective interventions both at individual and population level, in order to reduce the prevalence of HIV/AIDS among youth in Botswana.

\section{Limitations}

This paper is limited by the use of secondary data in the sense that in-depth-analysis of the attitudes and beliefs of youth about ARVs could not be explored beyond the given variables. Despite the aforementioned limitation, data provides vital insights on the attitudes and beliefs of youth about ARVs and the influence of such beliefs and attitudes on their sexual behavior.

\section{Ethical Statement}

The National AIDS Coordinating Agency and Statistics Botswana adhered to all the ethical considerations during the period of the survey. Respondents were given the chance to sign the informed consent forms and the survey was approved by the ethical review board in the Ministry of Health.

\section{Acknowledgements}

I wish to thank Statistics Botswana and National AIDS Coordinating Agency for providing Botswana AIDS Impact Survey IV dataset used for this article. I also wish to thank Department of 
Population, University of Botswana for availing resources for writing this article.

\section{References}

1. Central Statistics Office (2008) The health Statistical Report, Government Printers, Gaborone.

2. National AIDS Coordinating Agency (2009) National AIDS Council Report on HIV/AIDS Programme Performance, Government Printers, Gaborone.

3. Colvin M., AbdoolKrim SS., Connoly C., Hoosen AA, Ntuli N (1998) HIV infection and asymptomatic sexually transmitted diseases in rura South African community. International Journal of sexual Transmitted Diseases and AIDS 9: 548-550

4. Grémy I, Beltzer N (2004) HIV risk and condom use in the adult heterosexual population in France between 1992-2001-Return to the starting point? AIDS 18: 805-809.

5. Abbas UL, Anderson RM, Mellows JW (2006) Potential Impact of Antiretroviral therapy on HIV-1 transmission and AIDS mortality in resource limited Settings. Acquired Immune Defic Syndr 41:632-641.

6. Sweat M, Gregorich S, Sangiwa G, Furlonge C, Balmer D (2000) Cost effectiveness of voluntary HIV-1 counselling and testing in reducing sexual transmission of HIV-1 in Kenya and Tanzania. Lancet 356:113-121

7. Kalichman SC, Simbayi LC (2003) HIV testing attitudes, AIDS stigma and voluntary HIV counselling and testing in Black Township in Cape, South Africa. Sex Trans Infect 79: 442-447.

8. Stephens LL, Bachhuber MA, Seloilwe E, Gungqisa N, Mmelesi M, et al. (2012) HIV-Related knowledge, attitudes, and practice among educated young adults in Botswana. J AIDS HIV Res 4: 159-164.

9. Kennedy C, O'Reilly K, Medley A, Sweat, M (2007) The impact of HIV treatment on risk behavior in developing countries: A systematic review. AIDS Care 19: 707-720.

10. Batenganya M, Colfax G, Shaffer LA, Kityo C, Mugyenyi P, et al. (2005) Antiretroviral theraphy and sexual behavior: A comparative study between antiretroviral-naïve and experienced patients at an urban HIV/ AIDS care and Research center in Kampala, Uganda. AIDS Patient Care STDs 19:760-768.

11. National AIDS Coordinating Agency (2014) Botswana 2013 Global AIDS Response Report, Government Printers, Gaborone.

12. Majelantle RG, Keetile M, Bainame K, Nkawana P (2014) Knowledge, Opinions and attitudes towards HIV and AIDS among Youth in Botswana. J Glob Econ 2: 108 .

13. Central Statistics Office (2008) Botswana AIDS Impact Survey Statistical Report. Government Printers, Gaborone.
14. Bandura A (1989) Perceived self-efficacy in the exercise of control over AIDS infection. In Primary Prevention of AIDS: Psychological Approaches. Sage Publications Inc, California, USA.

15. Hingson R, Strunin L (1992) Monitoring Adolescents Responses to the AIDS Epidemic; Changes in Knowledge, Attitudes, Beliefs and Behaviors. SAGE Publications 14:17-33

16. Kalichman SC, Eaton L, White D, Cherry C, Pope H, et al. (2007) Beliefs about Treatments for HIV/AIDS and sexual risk behaviors among men who have sex with men, 1997-2006. J Acquir Immune Def 38: 196-201.

17. Cohen CR, Montadon M, Carrico AW, Shiboski S, Bostrom A, et al. (2009) Association of attitudes and beliefs towards antiretroviral therapy with HIV-Seroprevalence in the general population of Kisumu, Kenya. PubMed Central Journal 4: e4573.

18. Mah T, Halperin DT (2010) Concurrent sexual partnerships and the HIV epidemic in Sub Sahran Africa. The evidence to move forward. AIDS and Behavior $14: 11-16$.

19. Ezekiel MJ, Talle A, Juma JM, Mnyika KS, Klepp KI (2008) Attitudes and perceived impact of antiretroviral therapy on sexual risk behavior among young people in Kahe, Moshi Rural District, Tanzania. Tanzan J Health Res 10: 203-212.

20. Cartner MN, Kraft JM, Koppenhaver T (2007) A bull cannot be contained in a single kraal; Multiple Concurrent sexual partnerships in Botswana. AIDS and Behavior Journal 11: 822-830.

21. Cu-Uvin S, Caliendo AM, Reinert S, Chang A, Juliano-Remollino C, et al (2000) Effect of highly active antiretroviral therapy on cervicovaginal HIV-1 RNA.AIDS 14: 415-421.

22. Quin TC, Wawer MJ, Sewankambo N, Serwadda D, Li C, et al. (2000) Viral Load and hetero sexual transmission of human immunodeficiency virus type 1. Rakai Project Study group. N Engl J Med 342: 921-929.

23. Boily M, Baggaley RF, Wang L, Masse B, White RG, et al. (2009) Heterosexual risk of HIV infection per sexual act; systematic review and meta-analysis of observational studies. Lancet Infect Dis 9: 118-129.

24. Letamo G, Bainame K (1997) The socioeconomic and cultural context of the spread of HIV/AIDS in Botswana. Government Printers, Gaborone.

25. Granick R, Gilks CF, Dye C, De Cock KM, Williams BG (2009) Universal Voluntary HIV testing with immediate antiretroviral therapy as a strategy for elimination of HIV transmission; A mathematical model. Lancet 373: 48-57.

26. Crepaz N, Hart TA, Marks G (2004) Highly active antiretroviral therapy and sexual risk behavior: A meta-analytical review. JAMA 292(1): 224-236.

27. Kelly J, Otto-Salaj LL, Sikkema KJ, Pinkerton SD, Bloom FR (1998) Implications of HIV treatment advances for behavioral research on HIV/ AIDS: Protease inhibitors and new challenges in HIV Secondary prevention. Health Pyschol 17: 310-319. 